$8-2020$

\title{
Changing prevalence of gestational diabetes mellitus during pregnancy over more than a decade
}

Aisha Sheikh

Lumaan Sheikh

Follow this and additional works at: https://ecommons.aku.edu/ pakistan_fhs_mc_med_diabet_endocrinol_metab

Part of the Endocrine System Diseases Commons, Endocrinology, Diabetes, and Metabolism Commons, Maternal and Child Health Commons, and the Obstetrics and Gynecology Commons 
LEITER TO THE EDITOR

\section{Changing prevalence of Gestational Diabetes Mellitus during pregnancy over more than a decade}

Aisha Sheikh', Lumaan Sheik²

Dear Madam, Gestational Diabetes Mellitus (GDM) adversely affects the maternal and neonatal outcomes of pregnancy. Poorly controlled GDM is associated with macrosomia, polyhydramnios, operative deliveries, shoulder dystocia, neonatal hypoglycaemia, neonatal intensive care unit admission, neonatal hyperbilirubinaemia but the worst is the unexplained still births. ${ }^{1}$

We studied the prevalence of GDM at The Aga Khan University Hospital (AKUH), Pakistan over the period of 2005 till 2018. AKUH is a tertiary care center and on the average hosts more than 5000 deliveries per year.

We observed a progressive increase in the prevalence of GDM from the year 2005 till the year 2018 (figure). In 2005 it was $6.3 \%$ and remained stable at around $8 \%$ from 2006 till 2010. Over the ensuing years a progressive rise was seen. In 2011, it was 9.86\%. Now in 2017 and 2018, it's around $19 \%$. The average prevalence in initial 5 years of this study period was $8.09 \%$ (from 2005 till 2009) and in the last 5 years (2014 till 2018) 17.8\%. It has clearly more than doubled during this study duration.

This rise in prevalence of GDM is partly contributed by a change in GDM screening and diagnosis in our institute. Most of the OB/GYN consultants shifted to universal GDM screening practices and adopted the International Association of Diabetes in Pregnancy Study Group (IADPSG) criteria in the year 2012.2 However this increase in prevalence is a reflection of increasing back ground prevalence of Type 2 Diabetes Mellitus (T2DM) and obesity as well. Two recent surveys have shown the prevalence of Type 2 Diabetes in Pakistan at 26\% and 17.8\%.3,4 We need more data on GDM prevalence based upon the IADPSG criteria from different parts of Pakistan to know the exact burden of the disease.

Over more than a decade the prevalence of GDM is increasing, necessitating the need to improve the screening and management of GDM to improve the

1 Department of Medicine, The Aga Khan University, Karachi, Pakistan; 2Department of Obstetrics and Gynaecology, The Aga Khan University, Karachi. Correspondence: Aisha Sheikh. e-mail: aisha.sheikh@aku.edu

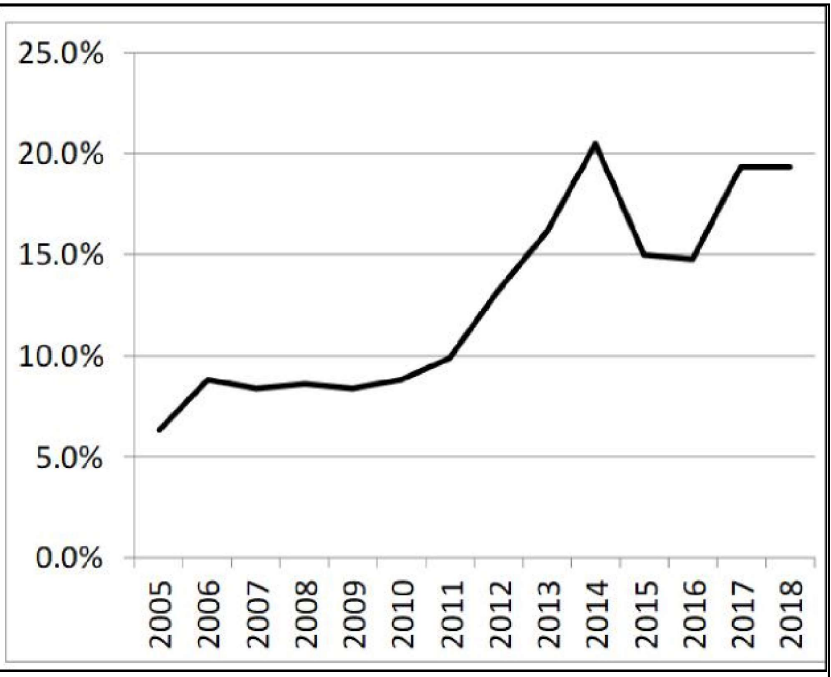

Figure: Prevalence of GDM per 100 live-births from year 2005-2018 in AKUH. maternal, foetal and neonatal outcomes. There is a need of more prospective studies on GDM from Pakistan. Centralized national GDM registry, post-partum Diabetes risk reduction strategies, public awareness and health care professional's (HCPs) GDM training workshops are all the need of the hour. There is a dire need of public and private partnership, involvement of HCPs at primary, secondary and tertiary care for concerted efforts to manage GDM and to implement strategies to reduce the risk of DM in the mother and the baby in the Coming years.

Acknowledgement: We are grateful to Ms Javeriah Khan, Associate at HIMS for helping us with the medical records of pregnancies affected by GDM.

Disclaimer: None.

Conflict of interest: None.

Funding disclosure: None.

\section{References}

1. Metzger BE, Buchanan TA, Coustan DR, De Leiva A, Dunger DB, Hadden DR, et al. Summary and recommendations of the fifth international workshop-conference on gestational diabetes mellitus. Diabetes Care. 2007; 30:S251-60.

2. International Association of Diabetes and Pregnancy Study Groups Consensus Panel. International association of diabetes and pregnancy study groups recommendations on the diagnosis and classification of hyperglycemia in pregnancy. Diabetes care. 2010; 33:676-82. 
3. Basit A, Fawwad A, Qureshi H, Shera AS. Prevalence of diabetes, pre-diabetes and associated risk factors: second National Diabetes Survey of Pakistan (NDSP), 2016-2017. BMJ Open. 2018; 8:e020961.
4. Aamir AH, Ul-Haq Z, Mahar SA, Qureshi FM, Ahmad I, Jawa A, et al Diabetes Prevalence Survey of Pakistan (DPS-PAK): prevalence of type 2 diabetes mellitus and prediabetes using $\mathrm{HbA} 1 \mathrm{c}$ : a populationbased survey from Pakistan. BMJ Open. 2019; 9:e025300.

https://doi.org/10.5455/JPMA.65585 